\title{
Implementation of modular MPPT algorithm for energy harvesting embedded and IoT applications
}

\author{
Krishnaveni Kommuri ${ }^{1}$, Venkata Ratnam Kolluru ${ }^{2}$ \\ ${ }^{1}$ Department of Electronics and Communication Engineering, Koneru Lakshmaiah Education Foundation, Vaddeswaram, \\ Andhra Pradesh, India \\ ${ }^{2}$ Department of Electronics and Computer Engineering, Koneru Lakshmaiah Education Foundation, Vaddeswaram, \\ Andhra Pradesh, India
}

\begin{tabular}{|c|c|}
\hline Article Info & ABSTRACT \\
\hline Article history: & \multirow{12}{*}{$\begin{array}{l}\text { The establishment of the latest IoT systems available today such as smart } \\
\text { cities, smart buildings, and smart homes and wireless sensor networks } \\
\text { (WSNs) are let the main design restriction on the inadequate supply of } \\
\text { battery power. Hence proposing a solar-based photovoltaic (PV) system } \\
\text { which is designed DC-DC buck-boost converter with an improved modular } \\
\text { maximum power point tracking (MPPT) algorithm. The output voltage } \\
\text { depends on the inductor, capacitor values, metal oxide semiconductor field } \\
\text { effect transistor (MOSFET) switching frequency, and duty cycle. This paper } \\
\text { focuses on the design and simulation of min ripple current/voltage and } \\
\text { improved efficiency at PV array output, to store DC power. The stored DC } \\
\text { power will be used for smart IoT systems. From the simulation results, the } \\
\text { current ripples are observed to be minimized from } 0.062 \text { A to } 0.02 \text { A } \\
\text { maintaining the duty cycle at } 61.09 \text { for switching frequencies ranges from } \\
300 \mathrm{kHz} \text { to } 10 \mathrm{MHz} \text { at the input voltage } 48 \mathrm{~V} \text { and the output voltage in buck } \\
\text { mode } 24 \mathrm{~V} \text {, boost mode } 100 \mathrm{~V} \text { by maintaining constant } 99.7 \text { efficiencies. The } \\
\text { improvised approach is compared to various existed techniques. It is noticed } \\
\text { that the results are more useful for the self-powered Embedded \& Internet of } \\
\text { Things systems. }\end{array}$} \\
\hline Received Oct 11, 2020 & \\
\hline Revised Feb 10, 2021 & \\
\hline Accepted Mar 5, 2021 & \\
\hline Keywords: & \\
\hline Buck-boost transitions & \\
\hline Internet of things & \\
\hline Maximum power point tracking & \\
\hline PV system & \\
\hline Remote monitoring & \\
\hline Wireless communication & \\
\hline & \\
\hline
\end{tabular}

This is an open access article under the CC BY-SA license.

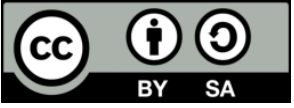

\section{Corresponding Author:}

Krishnaveni Kommuri

Department of Electronics and Communication Engineering

KLEF, Green fields, Vaddeswaram

Andhra Pradesh, India, 522502

Email: krishnavenikommuri@gmail.com

\section{INTRODUCTION}

Nowadays, energy consumption continues to increase. The world is therefore moving to the field of renewable energy sources as pollution-free, free of charge, and easy to access in remote areas. The green renewable energy sector is data-intensive and project-based, with a broad variety of targets and insights. For decades, utility producers, commercial and industrial customers have been working to optimize production and solar energy storage systems, while also helping to control costs [1]-[5]. Today the new system of things, such as the main design smart cities, smart buildings, and smart home and wireless sensor networks (WSN), is fed with battery power. Researchers concentrate primarily on solar PV systems to generate power as it is more stable and easier to load. The output voltage of the photovoltaic system is variable due to uncertainty in the radiances. However, to ensure a constant or controlled production voltage, DC-DC electronic power converters are used [6]-[11]. DC-DC converter based on green energy is becoming an increasingly attractive solution for these applications. A DC-DC converter technique was invented in the $1920 \mathrm{~s}$. It has been in the 
study for the past six decades and plays a predominant role in power engineering and driving. This is commonly used in many industrial applications, in computer hardware circuits, and the production of renewable energy. Power-based DC-DC converters are used to overcome the use of traditional single voltage divider circuits. Thus, the proposed DC-DC buck-boost constructed to have an improved modular MPPT algorithm based solar photovoltaic systems. This paper mainly focuses on performance analysis of minimum ripple current which the maximum efficiency of the converter. So that it leads to maximum power storage to the batteries in turn utilized for embedded \& IoT systems [12]-[30].

This article has been divided into various sections. Section 2 tells the literature review. Section 3 discusses PV system implementation for Embedded and IoT systems. Section 4 deals with the motivations towards quantum efficiency. Section 5 discusses the improvised DC-DC buck-boost converter model. Section 6 presents the flow chart design approach and simulation of improved modular MPPT algorithm section 7 described results and discussions of improvised MPPT for Embedded IoT systems. The paper is ended with a conclusion and future scope in section 8 .

\section{LITERATURE REVIEW}

A high frequency zero-voltage-switching (ZVS) synchronous non-inverting buck-boost converter in [1] for tens-of-Watt applications achieve ZVS under different load currents without raising voltage stress through power field effect transistor (FETs) by using two pairs of small-sized auxiliary inductors and condensers. DC-DC boost converter, [2] a conventional proportional integral (PI) controller, the modified incremental conductance MPPT technique is found that the modified Inc Cond MPPT tracks $7.4 \%$ more power than the traditional PI controller. A single-diode-model circuit [3] with the five parameters for a given environmental condition reflects the output of a photovoltaic (PV) module. The main goal here [4] is to achieve a circuit-based simulation model of a photovoltaic (PV) cell to estimate the functional cell's electrical behavior concerning changes in environmental parameters such as irradiation and temperature. To explore the variations between NIBB and traditional buck-boost converters [5] performed a detailed evaluation and study of these two converters in terms of their operating concepts, which here involves a multi-mode control mechanism and dual-edge modulation, and also studied the characteristics of switches and passive components in both converters.

A new dead zone compensation strategy to smooth the transition between operating modes is introduced in this article [6], reducing the voltage ripple, and increasing regulatory compliance while keeping high output. This paper [7], Weng et al. introduces a new modified two-switch buck-boost (TSBB) converter topology. While the converter has less conductive and semi-conductor switches than a traditional TSBB. After evaluating the shortcomings of current IQE measurement techniques, we present the recently an approach based on the improved $\mathrm{AB}$ mode in [8], called the reference-point room-temperature (RTRM) approach to demonstrate how the internal quantum efficiency (IQE) testing methods can be used to quantitatively evaluate their optoelectronic outputs. In certain power conversion applications, DC-DC converters with voltage boost capacity are commonly used, from fraction-of-volt to tens of thousands of volts at power rates ranging from milli watts to megawatt. The literature has reported on [9] various voltage boosting strategies in which simple energy storage elements (inductors and condensers) and/or transformers are used in the circuit in combination with switch (s) and diode (s). This paper proposes a [10], [11] noninverting buck-boost (NIBB) continuous-conduction mode (CCM) converter with a quick duty cycle calculation (FDCC) control and duty cycle locking technique. Nowadays the research is going in wide varieties of wireless sensor networks [12]-[19], embedded system [20]-[22], antennas with IoT applications [23]-[30].

\section{PV SYSTEM IMPLEMENTATION FOR EMBEDDED AND IOT SYSTEM}

Recent innovations focused on emerging technologies and upcoming startups working on energy harvest industry solutions. Many startups are working on a wide variety of solutions, looking at promising energy harvesting solutions for embedded systems \& IoT systems. Studying after many methods 4 important techniques were found. Those are: i) Mechanical energy harvesting, ii) Thermal energy harvesting, iii) Light energy harvesting, iv) Switches and sensors-electromagnetic energy harvesting. This paper concentrated on a green energy technique which is light energy harvesting. To obtain the maximum light energy, used the solar panel, and arranged it as shown in Figure 1. The working DC voltage can be sustained at the required loads. DC source activity is measured and shared among microcontroller (MCU) and sensors. The Buck-boost operations will be kept by the voltage regulator. The ultrasonic sensor (HC-SR04), air humidity sensor (DHT11), soil moisture sensors connected as displayed in Figure 1. The estimated power budget of the designed ultra-low power management circuit with a modular MPPT controller to extract maximum available 
power from the solar panel is tabulated in Table 1 . The product A, B, C, and D listed are rating with different powers that are seen with the respective efficiency in the simulation. A detailed description of implementations and simulations is discussed in the following sections.

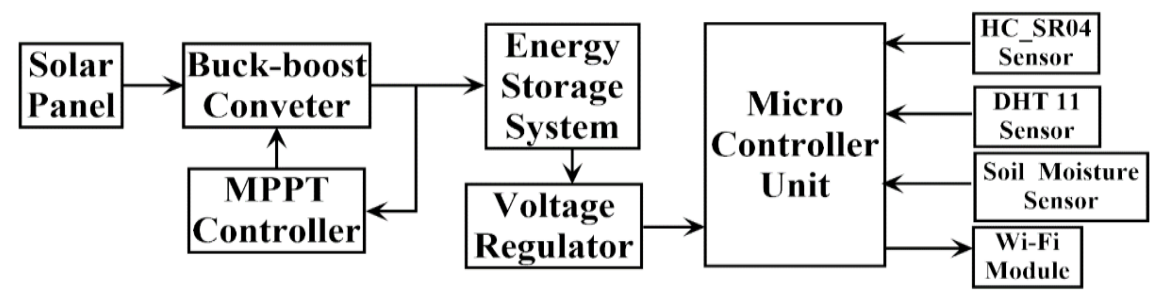

Figure 1. Energy harvest approach to IoT system

Table 1. Load evaluation calculator

\begin{tabular}{lll}
\hline Device Name & Estimated Power in $\mathrm{mW}$ & Efficiency \\
\hline Product A & 10 & 99.97 \\
Product B & 15 & 99.95 \\
Product C & 20 & 99.94 \\
Product D & 25 & 99.91 \\
\hline \multicolumn{2}{l}{ Note: Under Power loss $0.49 \mathrm{uW}, \mathrm{f}=300 \mathrm{KHz}$ to $10 \mathrm{MHz}$}
\end{tabular}

\section{MOTIVATION TOWARDS QUANTUM EFFICIENCY}

The aim of working on a component level analysis for the improvised modular MPPT algorithm is, a single-diode PV cell found the relationship between the quantum efficiency and diode current [3]. It improvises the MPPT point and efficiency of the PV system. The term quantum efficiency $(\mathrm{QE})$ is derived by an incident photon to converted electron (IPCE) of a photosensitive device.

The quantum efficiency of solar cellsis often considered into 2 types. External quantum efficiency (EQE) is defined as the no.of carriers collected by the solar cell to the no.of photons shining on the solar cell. The ratio of no.of charge carriers collected by the solar cell to no.of photons that are absorbed on the solar cell is called internal quantum efficiency (IQE). The IQE is always larger than the EQE. In this aspect, [5] considered IQE for improvisations. If all photons of a given wavelength are absorbed and the resulting minority carriers are captured, then unity is the quantum efficiency at that wavelength. The quantum efficiency for energy-saving photons below the bandgap is zero. Quantum efficiency is decreased for most solar cells because of recombination. A mathematical equationused is shown in [2]. In the ideal case scenario quantum efficiency is a function of wavelength, and electron can be written as (1),

$$
\eta(\lambda, \mathrm{e})
$$

where $\eta$ is a function of wavelength $(\lambda)$ and charge of an electron (e).

The diode current equation is expressed as (2),

$$
I_{d}=I_{0}\left(e^{q v / n_{s} v_{t}-1}\right)
$$

Under conditions where significant recombination of carriers in the diode transfer zone V-I characteristic can be observed. Where Io extremely important parameter as larger recombination leads to larger Io. $\mathrm{I}_{0} \infty$ related combination of reverse saturation current.

$$
I=I_{V}-I_{R}\left[\exp (q v / 2 k T]-I_{0}[\exp (q v / 2 k T]-1\right.
$$

To find open circuit voltage Voc, I become zero,

$$
0=I_{V}-I_{R}\left[\exp (q v / 2 k T]-I_{0}[\exp (q v / 2 k T]-1\right.
$$


Assume, $k T / q=260 m v \in v_{i}$, $\exp \left(\frac{q v}{2 k T}\right) \approx \exp \left(\frac{q v}{k T}\right)$

Substitute, $\exp \left(\frac{q v}{2 k T}\right)=Y$ in (4) becomes (5),

$$
-I_{0} Y^{2}-I_{R} Y+I_{V}=0
$$

By solving (5)

$$
Y=\frac{I_{R} \pm \sqrt{I^{2}} R+4 I_{0} I_{V}}{-2 I_{0}}
$$

Relating to $\mathrm{I}_{0}$, apply modulus on both sides the simplified given below,

$$
I_{0} \infty \phi
$$

From the above, it's been proved that the dark saturation current of the solar PV cell directly proportional to quantum efficiency. It's observed that $\mathrm{I}_{0}$ improves then there is more possibility of reaching the MPPT point for the given radiance which is useful to store the DC power. The detailed improvisations are discussed in the following sessions.

\section{IMPROVISED PV SYSTEM DC-DC BUCK BOOST CONVERTER MODEL}

The general configuration of the Buck-Boost converter is shown in Figure 2. The DC-DC boost converter [1] is a power electronicsdevice is also called as a step-up converter. Step down conversion also can be designed if it is considered as DC-DC Buck-Boost converter.

- Step-down converter

- Step-up converter

The circuit operation can be divided into two modes.

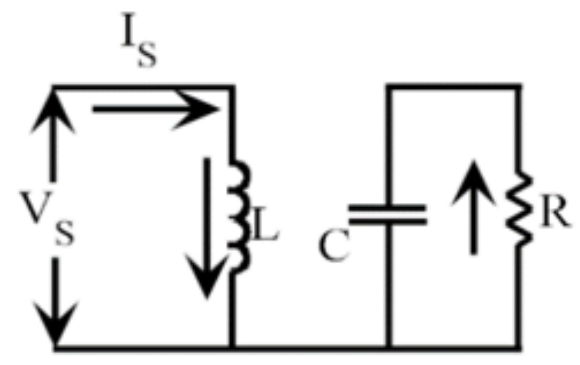

(a)

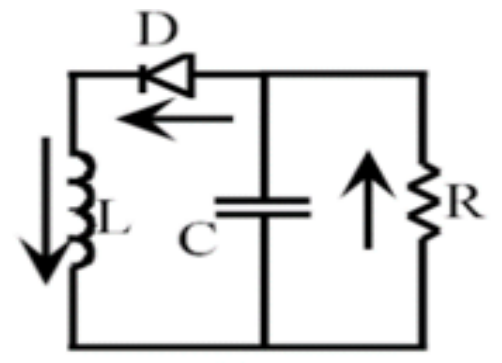

(b)

Figure 2. Configuration: (a) Buck-Boost converter in mode 1, (b) Buck-Boost converter in mode 2

During mode 1 Figure 2(a), the switch $\mathrm{S} 1$ is turned on and the diode D is reversed biased. In mode 1 the input current, which rises, flows through inductor L and switch S1. In mode 2 Figure 2(b), the switch S1 is off and the current, which was flowing through the inductor, would flow through L, C, D, and load. In this mode, the energy stored in the inductor (L) is transferred to the load and the inductor current (IL) falls until the switch S1 is turned on again in the next cycle. The simplified schematic [2] of a DC-DC inverting buckboost converter is shown in Figure 2. Most converter designs assume that a closed power switch has zero volts across it.

In general, this is a valid assumption that reduces design complexity. The circuit includes MOSFET, Diode, R, L, C components, and Control circuit. The fact that the power conversions have a finite resistance means that there will be a non-zero voltage over it during its on/off time operation thus MOSFET can be placed to fetch this operation. A MOSFET with fast switching speed [6] should be selected. Efficiency goes 
up when the switching speed increases. The diode is selected with the smallest reverse leak current () for light load and higher efficiency. The resistance is selected as $100 \mathrm{Ohm}$ because it gives the perfect DC-DC buck-boost operation with the below design,

$$
R_{l}=\frac{\left(V_{o u t}-0.7\right) h_{f e}}{I s c\left(I_{c}\right)-R_{e x t h}}
$$

To select the required inductance $\mathrm{L}$ can be represented as (8),

$$
L=\frac{V_{i}-D}{I_{l(p-p)} f_{s w}}
$$

The average inductor currentis calculated as (9),

$$
I_{l(\text { avg })}=\frac{I_{0}}{1-D}
$$
inductor is,

The input capacitance is required to hold up the input voltage when energy is decreasing in the

$$
\frac{(1-D)}{f_{s w}}
$$

The minimum effective values of the capacitor $\mathrm{Ci}(\mathrm{min})$ can be represented as (11),

$$
C_{i(\min )}=\frac{I_{l(\text { avg })} D}{f_{s w}\left[V_{i(p-p)}-I_{(p-p)}\right] E S R C_{0}}
$$

ESR represents [7] the equivalent series resistance of the input capacitor and it is recommended and selected of the order of value $100 \mathrm{Ohm}$. The output capacitance is required to supply the energy to the load when energy is increasing in the inductor,

$$
\frac{D}{f_{S W}} C_{O(\min )}=I_{0} \frac{D}{f_{S W}}\left[V_{0(p-p)}-\frac{I_{0}}{1-D}+\frac{I_{l(p-p)}}{2}\right] E S R C_{0}
$$

In the design of the Inverting Buck-boost converter Maximum duty cycle D gives at minimum input voltage and can be specified as (13),

$$
D=\frac{V_{0}+V_{f}}{V_{0}+V_{f}+V \min }
$$

From the reference [3] and rearrange the (13),

$$
\frac{V_{0}}{V_{i}}=\frac{D}{1-D}
$$

Controls circuit setup and simulation are shown in Figures 3 and 4. The output of the circuit is pulse which is given to the MOSFET gate and the input voltage is set to $48 \mathrm{~V}$.A reference voltage is given according to Buck/Boost operations here it is designed for buck mode $24 \mathrm{~V}$ boost mode $100 \mathrm{~V}$. Time sweep is taken for 4 seconds. Input voltage $48 \mathrm{~V} \mathrm{dc}$, output voltage Vo $24 / 100 \mathrm{~V} \mathrm{dc}$, inductor L=10 e-6 H, capacitor $\mathrm{C}_{0}=40 \mathrm{e}-3 \mathrm{~F}$, resistance $\mathrm{R}_{\mathrm{l}}=100 \mathrm{Ohm}$, Switching Frequency $\mathrm{f}_{\mathrm{sw}}=10 \mathrm{KHz}$. Ripple current is calculated as (15), 


$$
D_{i}=\frac{I_{\text {ripple }} I_{\text {out }} V_{\text {out }}}{V_{\text {in }}}
$$

Where Di is input current ripple Iout estimation for the inductor current,

$$
I_{\text {out }}=\frac{P_{\text {out }}}{V_{\text {out }}}
$$

Substituted the values in (12) can be written is being as (17),

$$
\begin{aligned}
& V_{0}=\frac{I_{0} D}{f_{s w} C_{0}}+\frac{I_{0}}{1-D}+\frac{I_{l(p-p)}}{2}+\operatorname{ESRC}_{0} \\
& V_{0}=I_{0}\left[\frac{D}{f_{s w} C_{0}}+\frac{1}{1-D}\right]+\frac{I_{l(p-p)}}{2}+E S R C_{0}
\end{aligned}
$$

Assume $\mathrm{D}=1$, in (17) becomes,

$$
f_{s w}=\frac{I_{0}}{V_{0} C_{0}}
$$

It is been seen by relating that the (4) noted that switching frequency in (18) values observed from $300 \mathrm{kHz}$ to $10 \mathrm{MHz}$ results in a ripple current $0.02 \mathrm{~mA}$ shown in Table 2 . Switching frequency is inversely proportional to the signal error which is shown in Table 2 . The switching frequency started from $300 \mathrm{kHz}$ for $\mathrm{L}=33.32 \mathrm{uH}$ and saw a ripple current of $0.62 \mathrm{~mA}$. Repeated the same observations till $10 \mathrm{MHz}$ for $\mathrm{L}=1 \mathrm{uH}$ where ripple current is $0.02 \mathrm{~mA}$. It is gradually minimized to 0.02 for the given input specifications. It is seen that minimum the Inductor and capacitance value changes lead the less in rising time to reach Buck-Boost designed values. The load resistance is constantly considered as $100 \mathrm{Ohm}$. Output DC voltage drives the maximum efficiency of the value 99.97 is in detail discussed in the following sections using the modular MPPT algorithm.

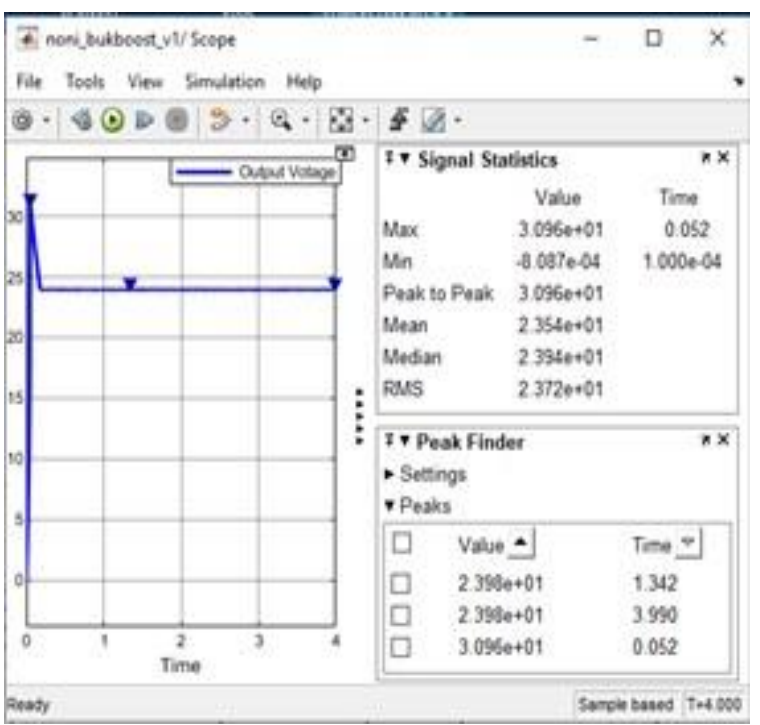

Figure 3. The simulation output from the BUCK converter

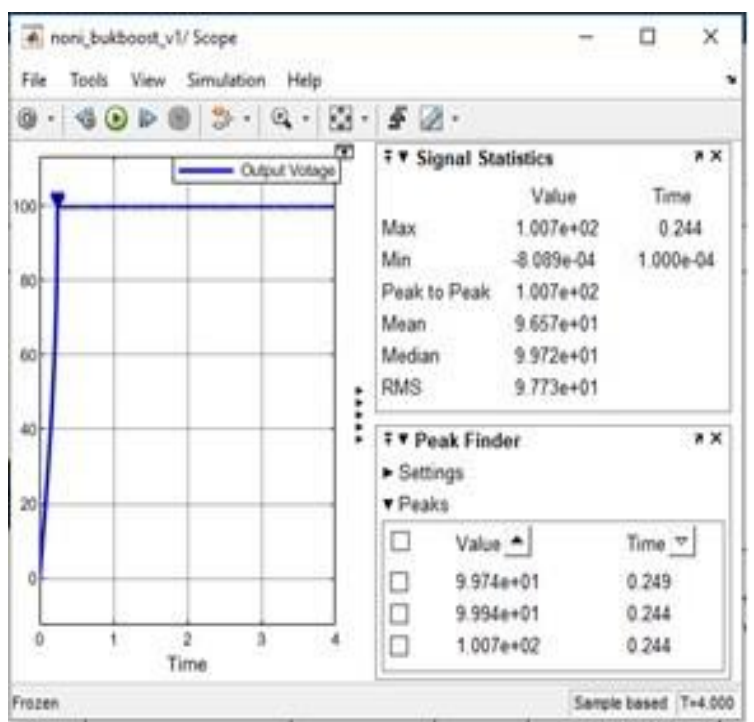

Figure 4. The simulation output from the BOOST converter 
Table 2. Load evaluation calculation

\begin{tabular}{ccc}
\hline Switching Frequency (in kHz) & Inductance (in uH) & Ripple Current (in mA) \\
\hline 300 & 33.22 & 0.62 \\
1000 & 9.9 & 0.19 \\
2000 & 4.98 & 0.09 \\
3000 & 3.32 & 0.06 \\
4000 & 2.49 & 0.05 \\
5000 & 1.99 & 0.04 \\
6000 & 1.66 & 0.03 \\
7000 & 1.42 & 0.03 \\
8000 & 1.25 & 0.02 \\
9000 & 1.11 & 0.02 \\
10000 & 1.00 & 0.02 \\
\hline
\end{tabular}

\section{FLOW CHART DESIGN APPROACH AND SIMULATION OF IMPROVISED MODULAR MPPT ALGORITHM}

The improvised PV system SIMULINK model and modular MPPT algorithm function shown in Figure 5 respectively. The irradiation and temperature [8] are fed to the solar panel. The virtual private network (Vpv) and invirtual private network (Ipv) monitored in Buck and Boost conventions. The component values of the modular MPPT algorithm programmed in a SIMULINK model is being as. PV module parameters like Vmpp, Impp, Voc, Iscof PM648 are 18.2 V, 2.2 A, 21.6 V, and 2.8 A respectively (at STC). In this PV system, five series-connected PV modules and 36 cells have existed. The switching frequency, output capacitance, input capacitance, inductance is $10 \mathrm{kHz}, 380 \mu \mathrm{F}, 330 \mu \mathrm{F}$, and $5 \mathrm{mH}$, respectively.

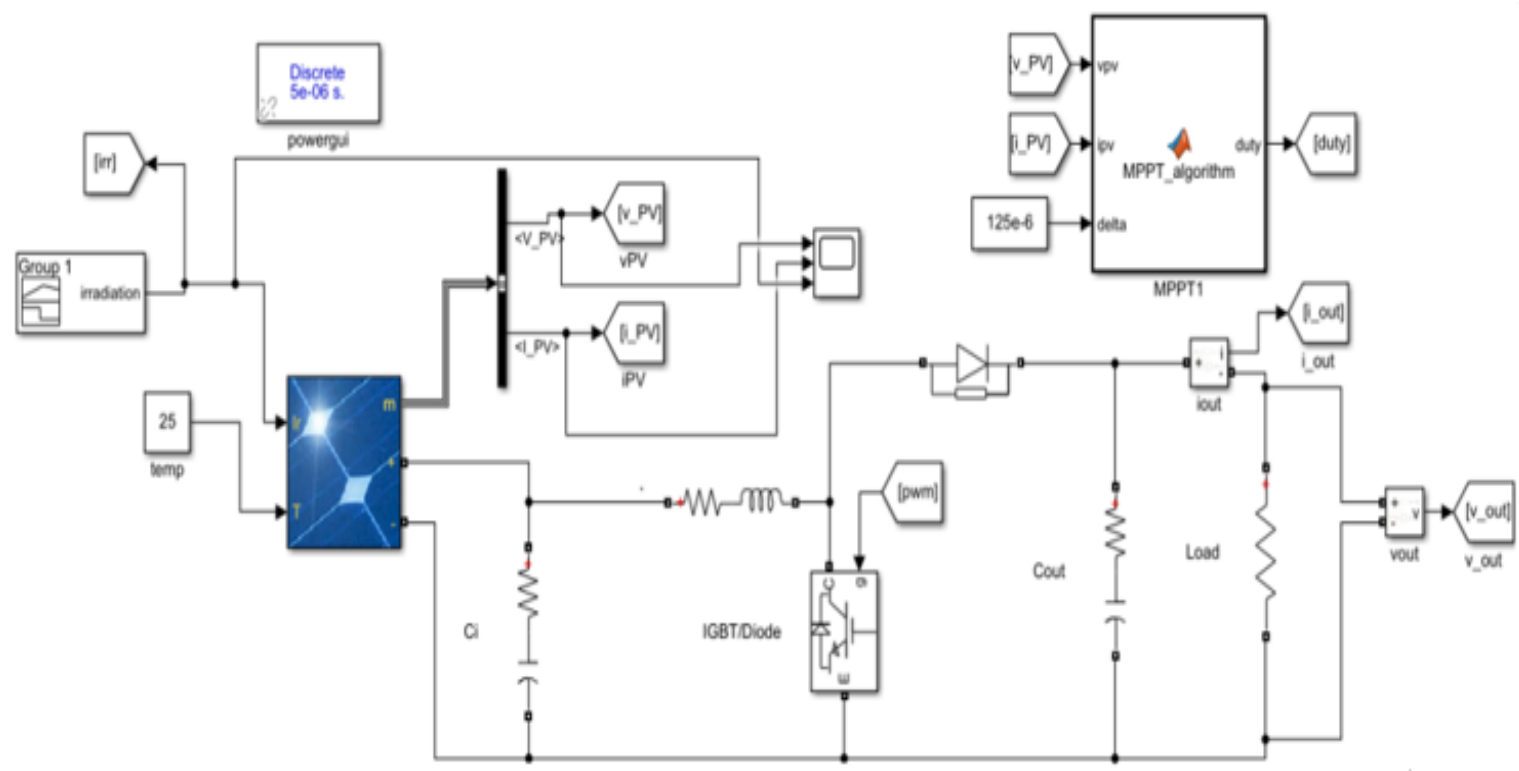

Figure 5. Structure of the improvised PV system with modular MPPT algorithm

Duty signal to determine the duty ratio of pulse-width modulation (PWM). Because to control of the power it depends on MPPT by its input irradiation. The modular MPPT algorithm is shown in Figure 6. Finds a global peak point by [9] seeking $\mathrm{dP} / \mathrm{dV}=0$ derivative. If power is not changing and voltage is not changing, then the derivative will be zero and the point will be maximum. Efficiency can be calculated by using this power. Because divide by zero might give a problem. Overall system efficiency is measured 95 .

The modular MPPT control algorithm is being as. Notations are represented in Figure 6. In the, duty-old $=\mathrm{A}$, duty-min $=\mathrm{B}$, duty-max=C, Duty=D. Initially duty cycle minimum and maximum values are taken as $\mathrm{B}=0, \mathrm{C}=0.85$. The selection of variable is taken which store the data and is named as persistent. It advisable [10] and easy to keep track of old data and new data by its difference. The algorithm will start with its B value. Calculating the difference, power and so on it repeats till it reaches its boost mode value. Here this is simulated for $100 \mathrm{~V}$. Once it reaches its maximum value efficiency calculated through which it finds an improved version of the PV system. 


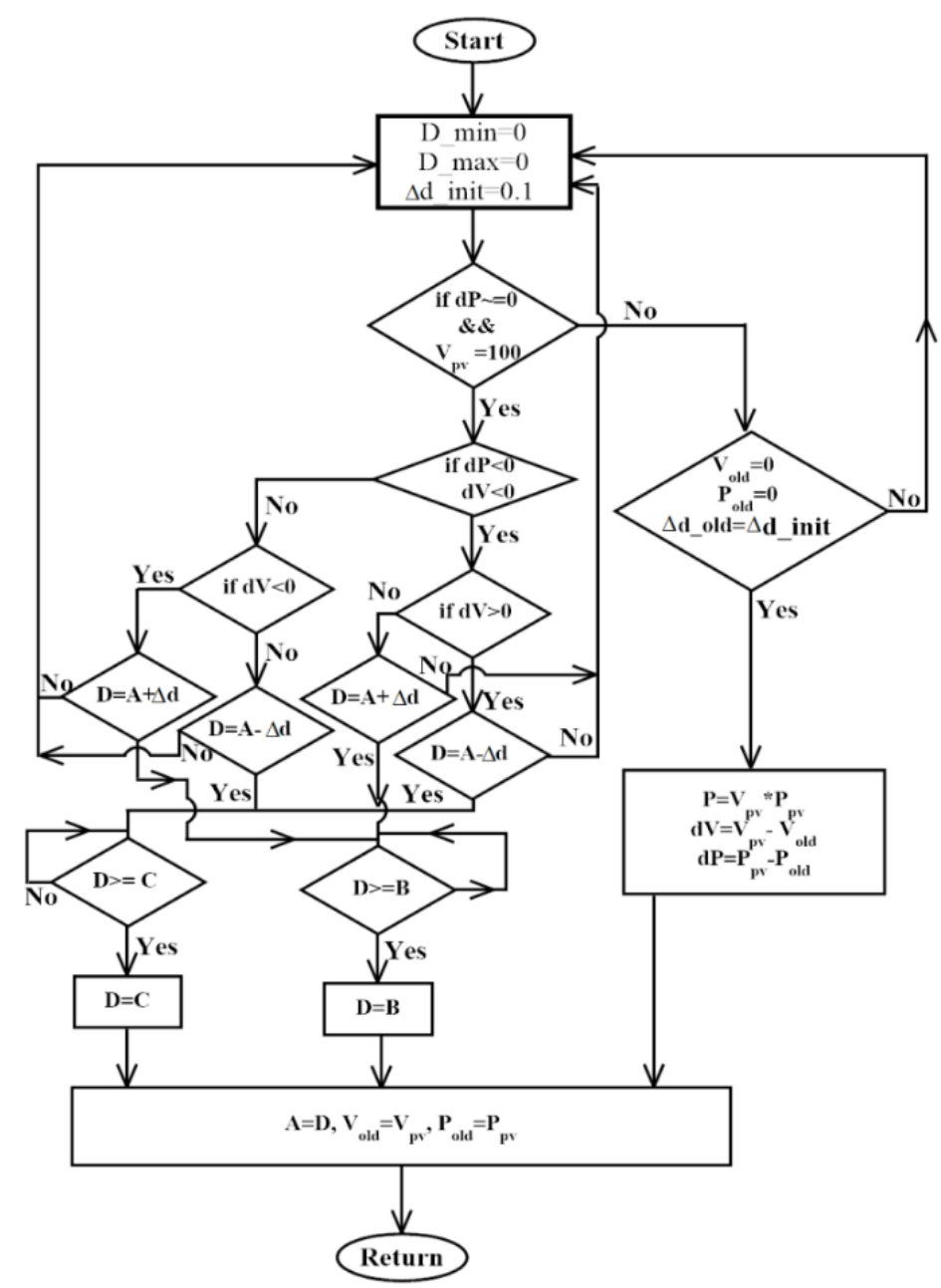

Figure 6. Flowchart of modular MPPT algorithm

\section{RESULTS AND DISCUSSION}

The simulation model of Simulink is displayed in Figure 7. When the PV system is fed with irradiation and temperature, the Vpv and Ipv Observed. The Ppv for the model is improvised by modular MPPT algorithm. It is comparedwith the ideal behavior characteristics. The signal statistics as shown in the plot named as Figure 7. It is implemented to bring the maximum efficiency of 9.971e-01 over the time of 4 seconds. The rising peak reaches its maximum point at time $0.8 \mathrm{sec}$ maintained MPPT to input irradiation. The difference value between P-Ideal and P-PV which is very minimum that $0-0.015$. It resembles the SSE error 0.6 in [1] proposal.

The development of today's new IoT technologies such as smart cities, smart houses, and smart homes and wireless sensor networks (WSNs) makes the key architecture constraint on insufficient battery power supply. The Solar-powered renewable energy-based PV system designed for DC-DC buck-boost converters with an upgraded modular MPPT algorithm proved the option for the above applications. This paper demonstrated the modeling and simulated analysis of min ripples current/voltage and calculated improved performance at the output of the PV system, to store DC power. From the simulation results, current ripples are found to be reduced from 0.062 A to 0.02 A retaining the service cycle at 61.09 for switching frequencies ranging from $300 \mathrm{kHz}$ to $10 \mathrm{MHz}$ at input voltage $48 \mathrm{~V}$ and output voltage in buck mode $24 \mathrm{~V}$, boost mode $100 \mathrm{~V}$ by maintaining the constant performance of 99.7 . The onboard power delivery circuit uses plenty of minimal shares of the overall resources produced for the embedded system as shown in Figure 7. Shortening the improvised PV system designed to withstand minimum power loss of $0.49 \mathrm{~W}$ operates a minimum DC voltage. By equalizing the power between the input and from the PV panel and electric power output.

To test the effectiveness of the modular MPPT algorithm, a comparison has been made among the performances of MPPTs like P\&O MPPT [11], adaptive P\&O MPPT [12] and auto-tuned MPPT [13], and 
self-tuned MPPT [1] implemented in the studied PV system. In Table 3, showing the differences between $\mathrm{P} \& \mathrm{O}$, adaptive $\mathrm{P} \& \mathrm{O}$, auto-tuned $\mathrm{P} \& \mathrm{O}$, and self-tuned MPPTs. For this, the following parameters are used for tracking of parameters such as variations in voltage, monitoring time, steady-state error (SSE), step size update rate (SSUR). i.e. with a step-change in irradiance.

From Table 3, it can be seen that the studied PV system with the improvised Modular MPPT has minimum tracking time $(0.8 \mathrm{~s})$, SSE $(0.015 \%)$, voltage fluctuation $(0.02 \mathrm{~V})$, and higher MPPT efficiency (99.7\%) compared to that of the other MPPTs tabulated in Table 3. From Table 3, SSUR is found to be variable for improvised modular MPPT which is very much minimum than that of the rest of the algorithms $(6 \times 10-3)$. Therefore, it has been reported that the studied PV system with modular MPPT performs better than P\&O MPPT, adaptive P\&O MPPT, auto tuned MPPT, self-tuned MPPT. Even if the P\&O algorithm is simple. It can be built on a low-cost microcontroller. Efficiency is weaker than modular MPPT PV system.

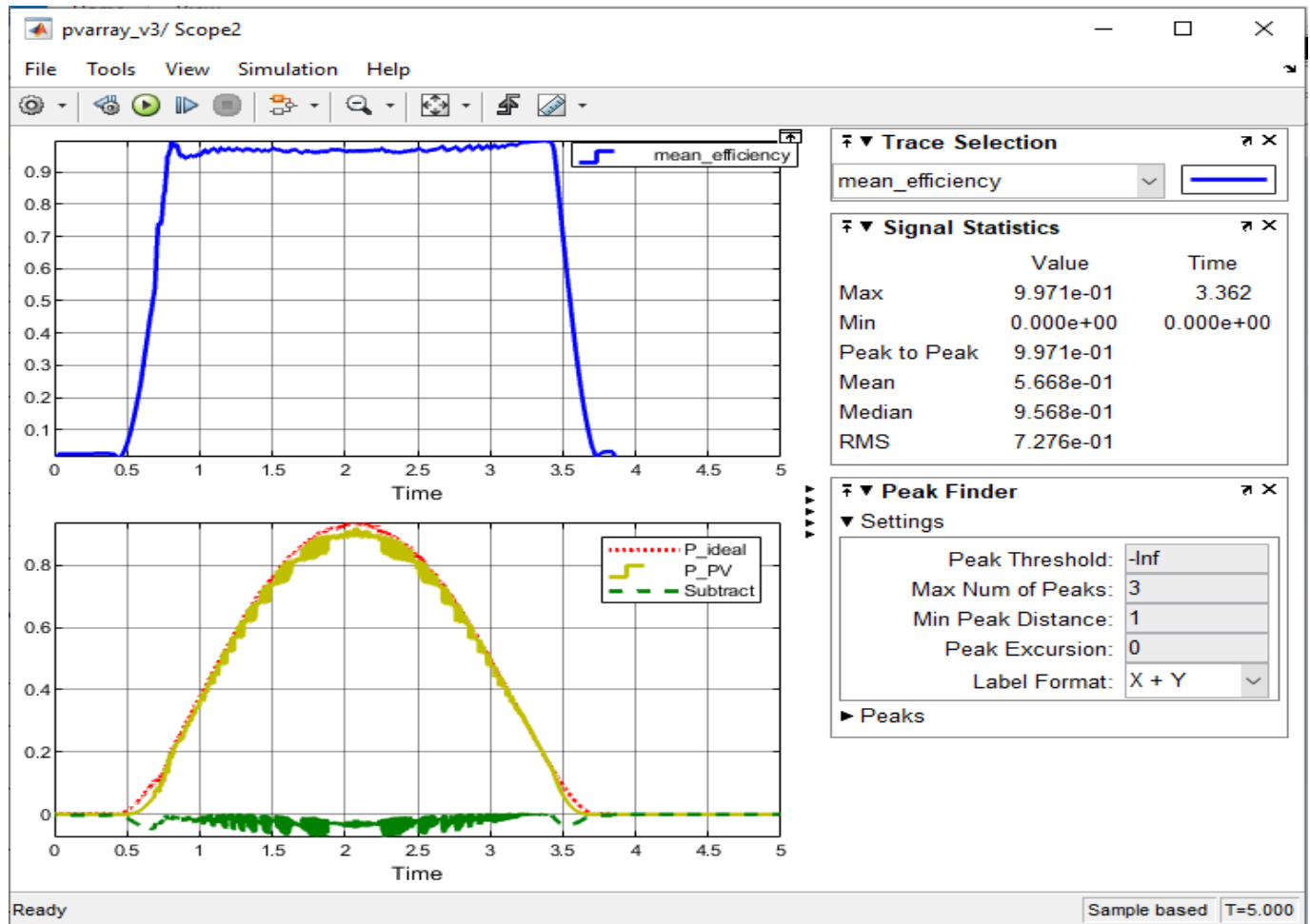

Figure 7. Maximum efficiency plot for P-Ideal P-PV and SSE

Table 3. Comparison of tracking parameters of the various MPPTS with improvised modular MPPT algorithm when solar radiation varies from $500 \mathrm{~W} / \mathrm{M} 2$ to $1000 \mathrm{~W} / \mathrm{M} 2$

\begin{tabular}{cccccc}
\hline Parameters & P\&O MPPT & Adaptive P\&O & Auto-tuned & Self-Tuned & Improvised \\
& {$[15]$} & MPPT [11] & MPPT [12] & MPPT [1] & Modular MPPT \\
\hline Tracking time & $1.6 \mathrm{~s}$ & $1.5 \mathrm{~s}$ & $0.9 \mathrm{~s}$ & $0.6 \mathrm{~s}$ & $0.8 \mathrm{~s}$ \\
SSE (\%) & 4.02 & 2.5248 & 0.03 & 0.012 & 0.015 \\
Voltage fluctuation & $8 \mathrm{v}$ & $5 \mathrm{v}$ & $1.5 \mathrm{v}$ & $1 \mathrm{v}$ & $0.02 \mathrm{v}$ \\
MPPT Efficiency (\%) & 96.5 & 97.8 & 98.6 & 99.3 & 99.7 \\
SSUR(s) & $6.0 \times 10^{-3}$ & Variable & Variable & Variable & Variable \\
\hline
\end{tabular}

\section{CONCLUSION}

The improvised modular MPPT algorithm started from the Single diode concept. Solved the relation between dark saturation current and quantum efficiency. This helps to store the largest DC power storage. The simulation results are tested in the control loop of the PV system through input PV voltage and a variable switching frequency supplies better tracking performance. DC-DC Buck-Boost conversions simulated with the smallest ripple current of $0.02 \mathrm{~mA}$. Improvised modular MPPT algorithm results in the smallest SSE error which is 0 to $<0.015$. As a part of future work would like to build an MPPT machine learning algorithm to make load evaluations required for embedded and IoT systems. 


\section{ACKNOWLEDGEMENTS}

This research work was carried and supported by DST- FIST grant number FST/ETI-410/2016(C) sponsored, internet of things excellence centre, KLEF. I would also like to show my gratitude to Dr. Venkata Ratnam Kolluru, Assoc. Prof, and, and KLEF for support and comments that greatly improved the manuscript, although any errors are our own and should not tarnish the reputations of these esteemed persons.

\section{REFERENCES}

[1] B. Subudhi and R. Pradhan, "A New Adaptive Maximum Power Point Controller for a Photovoltaic System," in IEEE Transactions on Sustainable Energy, vol. 10, no. 4, pp. 1625-1632, Oct. 2019, doi: 10.1109/TSTE.2018.2865753.

[2] V. R. Kolluru, K. Mahapatra, B. Subudhi, and T. Ramesh, "Real time implementation and comparison of PI and modified Inc Cond control algorithms for solar applications," 2014 IEEE 6th India International Conference on Power Electronics (IICPE), Kurukshetra, India, 2014, pp. 1-6, doi: 10.1109/IICPE.2014.7115780.

[3] Da Rosa, A. Vieira, and J. C. Ordonez, "Fundamentals of renewable energy processes," Academic Press, 2021.

[4] H. Fan, "Design tips for an efficient non-inverting buck-boost converter," Analog Applications Journal, Texas Instruments, 2014, 20-25.

[5] P. Liu and C. Chang, "CCM Noninverting Buck-Boost Converter With Fast Duty-Cycle Calculation Control for Line Transient Improvement," in IEEE Transactions on Power Electronics, vol. 33, no. 6, pp. 5097-5107, Jun. 2018, doi: 10.1109/TPEL.2017.2734808.

[6] L. Callegaro, M. Ciobotaru, D. J. Pagano, E. Turano and J. E. Fletcher, "A Simple Smooth Transition Technique for the Noninverting Buck-Boost Converter," in IEEE Transactions on Power Electronics, vol. 33, no. 6, pp. 4906-4915, Jun. 2018, doi: 10.1109/TPEL.2017.2731974.

[7] X. Weng et al., "Comprehensive comparison and analysis of non- inverting buck-boost and conventional buckboost converters," The Journal of Engineering, vol. 16, pp. 3030-3034, 2019.

[8] Shim, Jong-In, and Dong-Soo Shin, "Measuring the internal quantum efficiency of light-emitting diodes: towards accurate and reliable room- temperature characterization," Nanophotonics, vol. 7, no. 10, pp. 1601-1615, 2018, doi: https://doi.org/10.1515/nanoph-2018-0094.

[9] L. Callegaro, M. Ciobotaru, D. J. Pagano, E. Turano, and J. E. Fletcher, "A Simple Smooth Transition Technique for the Noninverting Buck-Boost Converter," in IEEE Transactions on Power Electronics, vol. 33, no. 6, pp. 4906-4915, Jun. 2018, doi: 10.1109/TPEL.2017.2731974.

[10] P. Liu and C. Chang, "CCM Noninverting Buck-Boost Converter With Fast Duty-Cycle Calculation Control for Line Transient Improvement," in IEEE Transactions on Power Electronics, vol. 33, no. 6, pp. 5097-5107, Jun. 2018, doi: 10.1109/TPEL.2017.2734808.

[11] H. Sharma, M. Sharma, C. Sharma, A. Haque, and Z. A. Jaffery, "Performance Analysis of Solar Powered DC-DC Buck Converter for Energy Harvesting IoT Nodes," 2018 3rd International Innovative Applications of Computational Intelligence on Power, Energy a nd Controls with their Impact on Humanity (CIPECH), Ghaziabad, India, 2018, pp. 26-29, doi: 10.1109/CIPECH.2018.8724183.

[12] N. S. D'Souza, L. A.C. Lopes, and X. J. Liu, "Comparative study of variable size perturbation and observation maximum power point trackers for PV systems," Electric Power Systems Research, vol. 80, no. 1, pp. 296-305, 2010, doi: 10.1016/j.epsr.2009.09.012

[13] W. Xiao, M. G. J. Lind, W. G. Dunford and A. Capel, "Real-Time Identification of Optimal Operating Points in Photovoltaic Power Systems," in IEEE Transactions on Industrial Electronics, vol. 53, no. 4, pp. 1017-1026, Jun. 2006, doi: 10.1109/TIE.2006.878355.

[14] M. N. M. Hussain, A. M. Omar, and A. A. A. Samat, "Identification of Multiple Input-Single Output (MISO) model for MPPT of Photovoltaic System," 2011 IEEE International Conference on Control System, Computing and Engineering, Penang, Malaysia, 2011, pp. 49-53, doi: 10.1109/ICCSCE.2011.6190494.

[15] A. López-Vargas, M. Fuentes, and M. Vivar, "IoT Application for Real-Time Monitoring of Solar Home Systems Based on Arduino ${ }^{\text {TM }}$ With 3G Connectivity," in IEEE Sensors Journal, vol. 19, no. 2, pp. 679-691, Jan. 2019, doi: 10.1109/JSEN.2018.2876635.

[16] T. Kalaipriyan, D. Rajaguru, J. Amudhavel, T. Vengattaraman and P. Sujatha., "Monkey King Algorithm For Solving Minimum Energy Broadcast In Wireless Sensor Network," Advances and Applications in Mathematical Sciences, vol. 17, no. 1, pp. 129-145, 2017.

[17] N. Srikanth and M. S. Prasad, "Energy-efficient trust node based routing protocol (EETRP) to maximize the lifetime of wireless sensor networks in Plateaus," International Journal of Online and Biomedical Engineering (IJOE), vol. 15, no. 06, pp. 113-130, 2019.

[18] A.V. Prabu and G. Kumar, "Performance Analysis and Lifetime Estimation of Wireless Technologies for WSN (Wireless Sensor Networks) /IoT (Internet of Things) Application," Jour of Adv Research in Dynamical and Control Systems, vol. 11, no. 1, pp. 250-258, 2019.

[19] A.V. Prabu,Dr.G. Sateesh Kumar, "Hybrid MAC-based Adaptive Preamble Technique to Improve the Lifetime in Wireless Sensor Networks," Journal of Adv Research in Dynamical and Control Systems, vol. 11, no. 1, pp. 240-249, 2019.

[20] A. Omairi, Z. H. Ismail, K. A. Danapalasingam, and M. Ibrahim, "Power Harvesting in Wireless Sensor Networks and Its Adaptation With Maximum Power Point Tracking: Current Technology and Future Directions," in IEEE Internet of Things Journal, vol. 4, no. 6, pp. 2104-2115, Dec. 2017, doi: 10.1109/JIOT.2017.2768410. 
[21] B. Tadikonda, A. V. Prabu, K. R. Rao, and P. S. G. A. Sri, "Secured door lock system based on fingerprint authentication," Accepted in Journal of Advanced Research in Dynamical and Control Systems, vol. 10, no. 02, pp. 473-480, 2018.

[22] K. Srinivas, A. V. Prabu, and K. Sambasivarao, "A Real-Time Prototype Model for Enhancing the Security Features in the ATM Units," International Journal of Innovative Technology and Exploring Engineering (IJITEE) vol. 8, no. 7, pp. 1936-1939, May 2019.

[23] R. L. R. L. Babu, D. Rambabu, A. R. Naidu, and R. D. Prasad, "IoT Enabled Solar Power Monitoring System," in International Journal of Engineering and Technology, vol. 7, no. 3, pp. 526-530, 2018, doi: 10.14419/ijet.v7i3.12.16172.

[24] P. Gopi Krishna, K. Sreenivasa Ravi, K Hari Kishore, K KrishnaVeni, K. N. Siva Rao, and R. D. Prasad., "Design and development of bi-directional IoT gateway using ZigBee and Wi-Fi technologies with MQTT protocol," International Journal of Engineering and Technology, vol. 7, no. 2.8, pp. 125-129, 2018.

[25] C. H. S. S. Krishna Gopal, A. V. Prabu, G. Sateesh Kumar, P. Gopi Krishna, "UPS parameter monitoring and controlling using IoT and GSM," International Journal of Pure and Applied Mathematics, vol. 116, no. 6, pp. 133-139, 2017.

[26] A. Vamseekrishna, B. T. P. Madhav, T. Anilkumar, and L. S. S. Reddy, "An IoT Controlled Octahedron Frequency Reconfigurable Multiband Antenna for Microwave Sensing Applications," in IEEE Sensors Letters, vol. 3, no. 10, pp. 1-4, Oct. 2019, Art. no. 3502204, doi: 10.1109/LSENS.2019.2943772.

[27] V. K. Allam, B. T. P. Madhav, T. Anilkumar, S. and Maloji, "A Novel Reconfigurable Bandpass Filtering Antenna for IoT Communication Applications," Progress In Electromagnetics Research, vol. 96, pp. 13-26, 2019, doi: 10.2528/PIERC19070805.

[28] A. V. Krishna, B. T. P. Madhav, R. Avinash, R, "A novel h-shaped reconfigurable patch antenna for IoT and wireless applications," International Journal of Innovative Technology and Exploring Engineering, vol. 8, no. 7, pp. 1757-1764, 2019.

[29] A. Vamseekrishna and B. T. P. Madhav, "A frequency reconfigurable antenna with Bluetooth, Wi-Fi, and WLAN notch band characteristics," International Journal of Engineering and Technology, vol. 7, no. 2.7, pp. 127-130, 2018.

[30] S. Varakumari, A. V. Prabu, K. Gopiram, and S. Venkatesan, "Coexistence and fair access on the shared channel for lteu and wi-fi," Journal of Advanced Research in Dynamical and Control Systems, vol. 9, no. 6, pp. 728-744, 2017.

\section{BIOGRAPHIES OF AUTHORS}

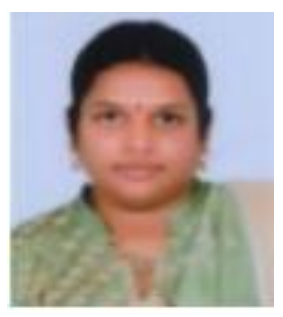

Krishnaveni Kommuri was born in Guntur, Andhra Pradesh, India, in 1983. She received M. Tech (Embedded systems \& VLSI) Degree from JNTU Hyderabad, Telangana in 2015. Pursuing Ph.D. in the Department of ECE, KLEF. Her research interests include embeddedsystems design, wireless sensor networks, design, and analysis of IoT Application Protocols. Energy optimization techniques using Solar based PV Systems and PV cells.

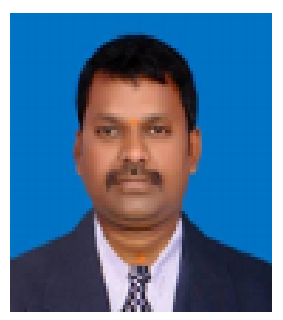

Venkata Ratnam Kolluru received M.Sc. (Electronics) Degree from Acharya Nagarjuna University, Andhra Pradesh in 2003,MTech (Embedded Systems) degree from Bharath University, Chennai, and Tamilnadu in 2006, and Ph. D (VLSI and Embedded Systems) degree in Electronics and Communication Engineering from NIT-Rourkela, India in 2016.His current research interests include IoT, VLSI \&Embedded Systems, Solar Cells, and MPPT. He published 6 research papers in different international conferences, 25 research papers published in various SCI and SCOPUS indexed international journals, and 4 more research papers communicated. Currently, his h-index is 6 , and the i10 index is 2 . 